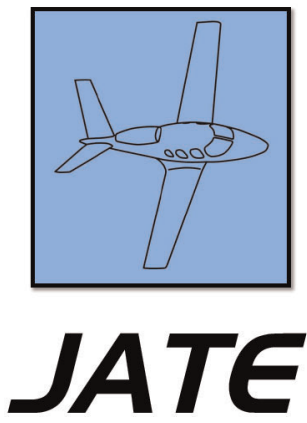

Journal of Aviation Technology and Engineering 3:1 (2013) 24-36

\title{
Flight Energy Management Training: Promoting Safety and Efficiency
}

\author{
Juan R. Merkt \\ Davis Aviation Center, Jacksonville University
}

\begin{abstract}
Poor aircraft energy management can lead to unsafe and inefficient operations. Despite their impact on safety and economy, energy management skills are not adequately taught or evaluated in civilian pilot training. This paper 1) addresses the need for better energy management training, 2) provides a conceptual and pedagogical framework for later curriculum development, and 3) suggests key attributes of an effective training program. To make the case, the study uses energy management to link safety and efficiency. It then synthesizes energy principles across disciplines and illustrates how such principles, once simplified, become powerful instructional tools. Finally, it suggests that an integrated, energy-centered, top-down training approach will lead to a better mental model of how the airplane works and, in doing so, to enhanced energy management and decision-making skills for safe and efficient operations.
\end{abstract}

Keywords: aircraft performance, controlled flight into terrain, energy efficiency management, energy balance, energy flow, energy gradient, energy height, energy maneuverability, energy safety management, energy state, flight control, flight energy management, kinetic energy, loss of control in flight, law of energy conservation, potential energy, specific excess power, runway excursion, total energy control system

\section{Introduction}

Aviation is a high-risk industry tasked with transporting people and goods safely and efficiently. Unsafe and inefficient operations pose a threat to public safety and confidence, and can cause significant financial losses to the aviation industry (BTRE, 2006). The incidence of in-flight energy crises leading to aircraft accidents (Airbus, 2005; Boeing, 2012; Jacobson, 2010) as well as the impact of wasted energy on increased operating costs (Airbus, 2004; Berglund, 2008; Boeing, 2004) suggest a need for better energy management training for pilots.

\section{About the Author}

Juan R. Merkt is director of the Davis Aviation Center at Jacksonville University. He has been involved in programs that educate and train aspiring airline pilots since 1994. His research interests involve aircraft and human performance limitations in extreme flight environments. His credentials include a Ph.D. degree from Harvard University and FAA Commercial Pilot and Gold Seal Flight Instructor certificates. Merkt is currently serving on the Board of Trustees of the Aviation Accreditation Board International (AABI) and is chair of its criteria and international committees. He has served as an AABI representative in the Next Generation of Aviation Professionals (NGAP) Task Force created by ICAO to address the worldwide shortage of skilled aviation professionals. Correspondence regarding this article may be directed to jmerkt@ju.edu. 
Energy is a fundamental, universal, and pervasive concept. Viewing an airplane in motion as an energy system can enhance a pilot's understanding of how the airplane "works" and how to manage its energy in flight. Airplanes convert energy as they move through the air, taking thermal energy produced from burning fuel and transforming it into the essentials of flight: altitude (potential energy) and airspeed (kinetic energy). In the process of creating the magic of flight, some of the energy gained from burning fuel is lost to the environment, generating a continuous flow of energy into and out of the airplane. Awareness of the aircraft's energy state and flow, as well as understanding the role of the flight controls for manually or automatically managing its energy, can enhance safety and efficiency. Once flying, an airplane will inexorably continue to transform and exchange various forms of energy until the very end of the flight, sometimes with disastrous consequences. It is up to the pilot to ensure that the airplane's energy is managed safely and efficiently from start to end.

Fighter pilots are well trained in energy management skills - their lives depend on the energy tactics needed to outmaneuver and outperform enemy aircraft during air combat (Shaw, 1985). Among civilians, glider and aerobatic pilots also understand and use energy management skills to maneuver safely and efficiently (FAA, 2003; Szurovy \& Goulian, 1994). Unfortunately, the same cannot be said of most pilots being trained through traditional civilian programs that do not appear to adequately teach or evaluate energy management skills. ${ }^{1}$ Such deficiency should be a cause for concern. The aviation industry is bracing for an unprecedented surge of pilot hiring worldwide (Boeing, 2011) at a time when most of the pilot supply comes, not from the military as in the past, but from civilian training programs (Duggar, Smith, \& Harrison, 2009).

This study examines the rationale and framework for flight energy management training and provides general guidelines for the design of such training programs. First, it uses energy management to link flight safety and efficiency. It then applies a multidisciplinary approach to develop the conceptual and pedagogical framework for future training programs. Finally, it suggests key attributes of an effective energy management training program.

\section{Energy Management as an Integrating Approach}

Merkt (1992) suggested using the airplane's power curve as a tool to demonstrate principles of flight control and

\footnotetext{
${ }^{1}$ Energy management competencies for pilot training are not addressed in FAA airman certification and training regulations (FAA, 2011a), FAA airman practical test standards (FAA, 2011b), or AABI aviation accreditation criteria (AABI, 2012a). In addition, "energy management" does not appear as a topic in aviation course titles or descriptions in flight education curricula as listed in the 2011-12 catalogs from the 27 universities and colleges that have AABI-accredited flight education programs (AABI, 2012b).
}

aircraft performance. This section examines more closely the usefulness of an energy-centered approach in linking safety (flight control) and efficiency (aircraft performance). From an energy management view, safety and efficiency can be regarded as "two sides of the same coin."

\section{Energy Safety Management}

The safety side of energy management is primarily concerned with flight control. One can define energy safety management as the process of monitoring and controlling the airplane's flight path and airspeed using procedures and techniques designed to mitigate hazards caused by unsafe or degrading energy states.

Improper flight energy management can be deadly. A significant number of fatal aircraft accidents have been associated with poor management of vertical flight path (potential energy) and/or airspeed (kinetic energy). Resulting from the inability of the pilot (or autopilot) to safely manage the airplane's energy state or restore it following an upset, loss of control in flight (LOC-I) has become the number one cause of fatal accidents in commercial (Boeing, 2012; Jacobson, 2010) and general aviation (EAA, 2011). A recent example of loss of control accidents is the crash of Colgan Air Bombardier Q400 in Buffalo, New York, which resulted in widespread media attention and sweeping new legislation for pilot qualifications (Jacobson, 2010). The next two leading causes of fatal accidents, controlled flight into terrain (CFIT), where an airworthy airplane is unintentionally flown into the ground (Boeing, 2012), and runway excursions during landing, where an airplane undershoots, overruns, or contacts the runway abnormally (Boeing, 2012), can also be at least partially attributed to poor energy awareness or management (Airbus, 2005). Although various contributing factors have been linked to each of the three leading causes of fatal accidents (Airbus, 2005; Clark, 2005; Cox, 2010; Jacobson, 2010), improper energy management appears to be a significant common denominator.

Several industry/government-led initiatives have addressed the above leading causes of fatal accidents. Such initiatives include the upset recovery training aid (URTA), aimed at decreasing loss-of-control-in-flight accidents (FAA, 2008); the terrain alert warning system (TAWS), developed for reducing controlled-flight-into-terrain accidents (Cox, 2010); and the approach and landing accident reduction (ALAR) tool kit, focused on decreasing runway excursion accidents (Clark, 2005). Although TAWS has been successful in reducing CFIT accidents (Jacobson, 2010), CFIT is still the second highest cause of jet fatalities worldwide (Boeing, 2012). Neither the URTA nor ALAR initiatives appear to have been effective in decreasing accidents caused by loss-of-control-inflight (Jacobson, 2010) and runway excursions (Cox, 2010), respectively.

The above initiatives constitute disparate remedial measures and may not sufficiently address the root causes 
of energy crises in flight. Basic energy safety training could go a long way in helping pilots acquire the knowledge and skills needed to operate safely. Such basic training could incorporate common mitigation strategies designed to prevent and detect unsafe energy states, and serve as the foundation for advanced drills, including emergency recovery techniques such as URTA (Jacobson, 2010).

\section{Energy Efficiency Management}

The efficiency side of energy management is primarily concerned with aircraft performance. One can define energy efficiency management as the process of monitoring and controlling the airplane's performance using procedures and techniques aimed at reducing the amount of fuel consumed per unit distance or time.

Energy efficiency is often associated with range or endurance performance in cruise flight (Hurt, 1965). However, energy efficiency also applies to other phases of flight and even ground operations. Thus, energycentered training may be ideal to develop energy management skills for efficient operations (Merkt, 1992). Although this view of aircraft performance emphasizes fuel-optimization strategies, training should also address other aspects of performance and assess trade-offs. Fuel efficiency is important, but there are times when other factors (e.g., safety, time-related performance, ATC restrictions) may take precedence over energy economy.

Fuel consumption is the second highest cost to airline operators (Stolzer, 2002; Vause, 2004), and proper energy management techniques can save fuel and decrease cost of flight operations (Airbus, 2004; Berglund, 2008; Boeing, 2004). Although fuel economy depends on many factors, some of which are beyond a flight crew's control (e.g., preflight actions by ground personnel and in-flight restrictions by air traffic control), in-flight procedures and piloting techniques can have the largest impact on fuel savings (Airbus, 2004; Boeing, 2004). Boeing estimates that a 1 percent reduction in fuel used per flight can result in fuel savings of up to 135,000 gallons per airplane per year (Boeing, 2004). At current jet fuel prices, that's up to $\$ 0.5$ million in savings per airplane per year.

Basic energy efficiency training could go a long way in assisting pilots develop energy conservation skills to save fuel and reduce operating costs. Obviously, flight crews must not compromise safety for efficiency. A benefit from an integrated approach, incorporating both energy control and performance, is that it may enhance the ability to assess the balance between safety and efficiency, helping pilots make critical decisions. As an example, consider an unsafe situation where fuel is running low. The pilot could slow down to maximum endurance speed, at the "bottom" of the power curve, in order to minimize fuel consumption and maximize time aloft. However, slowing down for maximum endurance would bring the airplane dangerously close to stall speed, which could result in loss of control. A properly trained pilot, caught between two unsafe situations (running out of fuel versus stalling), may decide to slow down to an intermediate speed that would still prolong time aloft and provide a higher margin of safety.

Note that in addressing the integration of energy safety and efficiency, emphasis is on altitude and airspeed control and related performance for flight in the "up-and-down" vertical plane, since most of the airplane's time and energy are spent flying straight-and-level, climbing, and descending. However, some of the airplane's energy is also spent maneuvering in the horizontal plane. Maneuvering along a curved flight path requires coordination of multiple flight controls (not just throttle and elevator) to rotate the airplane around its three axes and change its attitude. Obviously, maneuvering control errors can impact flight safety. For example, overbanking or excessive yawing during a turn could lead to an initial loss of control in flight. On the other hand, maneuvering performance can affect energy efficiency. Thus, excessive maneuvering can drain energy because of the increased load factor and resultant higher induced drag during turns (Hurt, 1965). In addition, as the airplane rotates around its axes, stability also becomes critical as it can affect both energy safety and efficiency. For instance, moving the center of gravity aft to improve fuel economy reduces longitudinal stability, which in turn makes controlling the airplane on the vertical plane inherently less safe (Barnard \& Philpott, 1989). Thus, an integrative energy approach seems ideal to address interactions among various aspects of control, stability, and performance and examine their relative impact on safety and efficiency.

Having established that an energy view is useful in linking flight safety and efficiency, the next section focuses on general energy principles that can be applied to flight control and aircraft performance. As it will become evident, the energy connection between control and performance is well rooted in the science of motion.

\section{Conceptual Framework for Energy Management Training}

Barring a few related findings, ${ }^{2}$ a literature review revealed a lack of energy management textbooks, studies, or curricula designed for training civilian pilots. Traditional textbooks on flight theory for pilots (e.g., Barnard \&

\footnotetext{
${ }^{2}$ In his classic book, Stick and Rudder, Langewiesche (1944) emphasizes the role of the elevator for exchanging altitude and airspeed as he describes the "zoom" technique and the "law of the roller coaster." In a short training guide for pilots, Airbus (2005) outlines energy management principles to control flight path and airspeed during the approach phase. In his online book, See How It Flies, Denker (2008) explains energy conversions and the effect of the flight controls on energy. Amelink, Mulder, van Paassen, and Flach (2005) apply total energy control principles to describe how pilots can control aircraft speed and altitude. Finally, Merkt $(1990 ; 1991 ; 1992)$ explores the instructional merits of a "top-down," energy-centered approach for training pilots. The top-down approach is discussed later in this paper.
} 
Philpott, 1989; Dole, 1989; Hubin, 1992; Hurt, 1965) neglect or insufficiently address energy management concepts. Fortunately, flight energy concepts rely on fundamental physics. In addition, energy management models have been applied successfully to address a wide range of problems dealing with self-powered motion, from designing safer automatic flight control systems for passenger aircraft (Lambregts, 1983), and helping fighter pilots win air combat battles (Shaw, 1985), to elucidating how animals move around efficiently (Pennycuick, 2003). Physics principles and energy models from other disciplines provide the conceptual framework for the proposed training program.

\section{Physics: Laws of Energy Conservation and Motion}

Energy management concepts are founded on basic principles of physics, namely the law of energy conservation, which defines the energy state of the airplane at any given time (Goodman \& Warner, 2001), as well as Newton's laws of motion that govern the airplane's translational (and rotational) movement through the air (Anderson, 2007). Energy and motion equations, such as those described below, provide the foundation for an energy-centered study of aircraft control and performance.

Applied to flight, the law of energy conservation defines the total mechanical energy of the airplane-its energy state-as the sum of its gravitational potential energy derived from height above the ground plus its kinetic energy acquired from speed through the air (Amelink et al., 2005; Goodman \& Warner, 2001; Rutowski, 1954):

$$
E=E_{\mathrm{pot}}+E_{\mathrm{kin}}=m g h+1 / 2 m V^{2}
$$

Where:

$$
\begin{aligned}
& E=\text { aircraft's total mechanical energy } \\
& E_{\text {pot }}=\text { gravitational potential energy }(m g h) \\
& E_{\text {kin }}=\text { kinetic energy }\left(1 / 2 m V^{2}\right) \\
& m=\text { aircraft's mass } \\
& g=\text { gravitational acceleration } \\
& h=\text { aircraft's altitude above a ground reference } \\
& V=\text { aircraft's velocity }
\end{aligned}
$$

In Equation 1, using energy as the common "currency" to measure how high and fast an airplane is flying, the law of energy conservation allows us to combine the airplane's altitude $(h)$ and airspeed $(V)$ and examine their relative contribution to its total energy. ${ }^{3}$ To put it differently,

\footnotetext{
${ }^{3}$ In this paper, the terms altitude and height ( $h$ ) are used interchangeably to refer to the vertical distance (e.g., feet) above a reference on the earth's surface. Usually, altitude is measured from sea level, while height is measured from ground level. The terms airspeed and velocity $(V)$ are also used interchangeably. Note that airspeed is a scalar quantity representing the magnitude of the airplane's speed through the air (e.g., knots), while velocity is a vector quantity denoting both magnitude and direction. Energy (or work), on the other hand, is a scalar quantity that can be measured in units such as foot-pounds or joules.
}

Equation 1 defines how much of the airplane's total mechanical energy is stored as potential energy (altitude) and kinetic energy (airspeed) at any given time.

Turning to the forces of motion, Newton's second law $(\Sigma F=m a)$ provides a simplified longitudinal point-mass equation depicting the summation of the forces acting on the airplane along its flight path (Anderson, 2007):

$$
T-D-W \sin \gamma=m a
$$

Where:

$$
\begin{aligned}
& T=\text { thrust } \\
& D=\text { drag } \\
& W=\text { aircraft's weight } \\
& \gamma=\text { angle of flight path with the horizontal } \\
& m=\text { aircraft's mass } \\
& a=\text { aircraft's acceleration }
\end{aligned}
$$

Equation 2 assumes that thrust $(T)$ acts almost nearly in the direction of the flight path. For most situations, except for flight at very high angle of attack, this is a reasonable assumption (Anderson, 2007; von Mises, 1945). Note that Equation 2 can be applied to climbing, level, or descending flight simply by making flight path angle $\gamma>0,=0$, or $<0$, respectively. Likewise, the equation can be applied to accelerating, constant speed, or decelerating flight by making acceleration $a>0,=0$, or $<0$, respectively. Certainly, when $\gamma=0$ and $a=0$, then $T$ $-D=0$, which represents the familiar steady-state equation for level, unaccelerated flight — where the airplane is maintaining a constant altitude and airspeed.

Reorganizing the terms in the above equation:

$$
T-D=W \sin \gamma+m a
$$

Equation 3 is a simple but significant rearrangement of the terms in Equation 2, since it allows us to combine flight path angle $(\gamma)$ and acceleration $(a)$ as a function of the difference between thrust and $\operatorname{drag}(T-D)$. The significance is that flight path angle $(\gamma)$ is associated with altitude changes, just as acceleration $(a)$ is associated with airspeed changes. But there is more to these energy and motion equations than meets the eye.

What may not be apparent by looking at the above equations is the fact that the law of energy conservation and Newton's second law of motion are intimately linked (Goodman \& Warner, 2001). This close relation is the crux of the energy view of flight control and performance. According to the law of energy conservation, energy can be converted from one form to another, but it can never be created or destroyed. Thus, the conservation law allows an airplane to exchange stored kinetic and gravitational potential energy while its total mechanical energy remains constant. During such exchange, one form of energy (e.g., potential energy) increases at the expense of another (e.g., kinetic energy). Simply put, airspeed can be traded for altitude and vice versa. The conservation law also dictates that energy can be added to or removed from the energy 
stored in an open system (i.e., the flying airplane). Of course, the energy gained is not created-it is transferred in from another system acting as the energy "source." Likewise, the energy lost is not destroyed-it is transferred out to another system acting as the energy "sink." Once airborne, the airplane gains energy through engine thrust $(T)$, the propulsive force generated from burning fuel, and loses energy through drag $(D)$, the retarding force that releases heat into the surrounding air (Amelink et al., 2005; Rutowski, 1954). Consequently, energy flows continuously into and out of the flying airplane. More importantly, there is a fundamental relationship between the energy flowing through the airplane and changes in its energy state.

Since energy cannot be created or destroyed, an energy balance must always exist between 1) the net flow of energy through a system (i.e., energy gain minus loss) and 2) the resultant change in total energy within the system (Cengel, 2007). The airplane's energy balance, central to both flight control and aircraft performance, can be expressed as follows ${ }^{4}$ :

$$
E_{\mathrm{T}}-E_{\mathrm{D}}=\Delta E
$$

Where:

$$
\begin{aligned}
& E_{\mathrm{T}}=\text { energy gained through thrust } \\
& E_{\mathrm{D}}=\text { energy lost through drag } \\
& \Delta E=\text { change in total mechanical energy }
\end{aligned}
$$

The energy balance equation can also be written on a per unit time basis, converting it into a time rate equation, where the dot over the letter symbolizes rate ${ }^{5}$ :

$$
\dot{E}_{\mathrm{T}}-\dot{E}_{\mathrm{D}}=\dot{E}
$$

Expressing the difference $\dot{E}_{\mathrm{T}}-\dot{E}_{\mathrm{D}}$ as a net total energy flow $\dot{E}_{\mathrm{T}-\mathrm{D}}$, and the rate of change of the airplane's total mechanical energy $\dot{E}$ as the sum of the rates of change of potential energy $\left(\dot{E}_{\text {pot }}\right)$ and kinetic energy $\left(\dot{E}_{\text {kin }}\right)$, the energy balance equation takes on a more useful form:

$$
\dot{E}_{\mathrm{T}-\mathrm{D}}=\dot{E}_{\text {pot }}+\dot{E}_{\text {kin }}
$$

As implied by Equation 6, the net total energy flow ( $\left.\dot{E}_{\mathrm{T}-\mathrm{D}}\right)$ - a direct function of the difference between thrust and drag $(T-D)$-determines whether the aircraft's total

\footnotetext{
${ }^{4}$ Rutowski (1954) championed the energy balance approach for analyzing aircraft performance. As explained in the next section, the same energy method can be used for solving flight control problems. Note that Equation 4 represents an approximation of the energy balance relationship because it neglects to account for the change in total mechanical energy caused by the change in aircraft weight as fuel is gradually burned in flight (Rutowski, 1954). The effect of weight change may be negligible when applying the energy approach to solve short-term control problems (e.g., Amelink et al., 2005), but it is critical to solve long-term performance problems such as those involving climb and range calculations (e.g., Pennycuick, 2003). For a complete analysis of the energy balance equation as it applies to aircraft performance, see Rutowski (1954).

${ }^{5}$ Energy (or work) per unit time is power, which can be measured in units such as horsepower or watts.
}

mechanical energy increases, decreases, or remains the same. Any change in total mechanical energy is, in turn, distributed over potential (altitude) and/or kinetic (airspeed) energy. For example, if $T-D$ is greater than zero, there is a positive net energy flow into the airplane, allowing it to climb and/or accelerate to a new (higher) energy state level. In sum, the left-hand side of the balance equation controls the net transfer of energy into or out of the airplane by the action of two forces ( $T$ and $D$ )- -hence regulating the rate of change of total mechanical energy; while the right-hand side controls the distribution of the net transferred energy between altitude $\left(\dot{E}_{\text {pot }}\right)$ and airspeed $\left(\dot{E}_{\text {kin }}\right){ }^{6}$ Thus, in examining basic principles of flight energy management, Newton's second law of motion (which dictates the rate of change of the airplane's total mechanical energy) is as important as the law of energy conservation (which governs the airplane's ability to transfer, distribute, store, and exchange energy).

As described in the next three sections, the relation between energy and motion laws has been exploited differently by two groups of engineers and a group of biologists in their energy approach for studying motion. Using the same set of energy and motion equations, one group of engineers has focused on developing principles for energy-based flight control (e.g., Lambregts, 1983), while a second group has concentrated on finding rules for energy-based aircraft performance (e.g., Rutowski, 1954). Biologists, on the other hand, have taken analogous energyforce relations one step further in order to examine the energy-based integration of motion control and performance (e.g., Dickinson et al., 2000). In addition, the ability of some animals to travel ultra-long distances without "refueling" has prompted biologists to develop energy models addressing not only the efficiency of extracting mechanical energy from fuel but also that of converting mechanical energy into motion (e.g., Pennycuick, 2003).

\section{Engineering: Total Energy Control System}

An important model for aircraft energy control comes from NASA-funded research conducted by Tony Lambregts while working at the Boeing Company (Lambregts, 1983). Applying energy concepts to design safer and more efficient automatic flight control systems, Lambregts developed the Total Energy Control System (TECS), a multi-input, multi-output (MIMO) automated system that integrates the autopilot (which operates the elevator) and the autothrottle for decoupled vertical flight path (altitude) and airspeed control. In MIMO automatic control systems, flight path and airspeed error signals are cross-fed to both autopilot and autothrottle. In contrast, in conventional single-input, single-output (SISO) systems,

\footnotetext{
${ }^{6}$ See Figure 1 in the next section for a visual representation of the energy balance equation.
} 
flight path and airspeed errors are independently controlled by the autopilot and autothrottle, respectively (Lambregts, 1983). The problem with SISO strategies is that, without coordinated use of the controls, the change in one variable (e.g., altitude) is always coupled with an unwanted change in the other variable (e.g., airspeed). In addition, under certain conditions, the inherent limitations of a typical SISO automatic control system can lead to unsafe situations such as loss of control in flight (Lambregts, Rademaker, \& Theunissen, 2008).

Significantly, the TECS/MIMO control system was designed from the ground up following energy management principles (Lambregts, 1983). The airplane has two primary devices to control altitude and airspeed: the throttle and the elevator. The question is: which device controls altitude and which one controls airspeed? Given that altitude and airspeed are intrinsically related to the aircraft's total energy, Lambregts reasoned that the problem of controlling these variables is basically one of managing energy. From an energy management view, he recognized that the throttle, which can rapidly increase or decrease the amount of thrust (energy gain), should be used to regulate the rate of change of the aircraft's total mechanical energy. Even though the latter is a function of both thrust and drag (Equation 5), the amount of drag (energy loss) mainly varies due to long-term changes in airspeed or limited deployment of high lift/drag devices that can only increase drag (Amelink et al., 2005; Lambregts, 1983). Therefore, most changes in total energy-demanded by new or corrective maneuvers - are initiated by changing thrust, not drag. In the long-term (i.e., once the targeted steady flight condition is achieved), engine thrust can be retrimmed to compensate for changes in drag and satisfy the new total energy demand (Lambregts, 1983). Next, Lambregts noted that the elevator, which can be used to trade the aircraft's potential energy for kinetic energy and vice versa, effectively controls the distribution of energy between altitude and airspeed. Thus, notwithstanding the debate about "single-input, single-output" strategies (Table 1), neither the throttle nor the elevator controls altitude and airspeed independently. Rather, to control altitude and speed effectively, both devices need to be coordinated following energy management rules. According to TECS principles then, the flight controls are really energy controls, where the throttle acts as the total energy controller and the elevator as the energy distribution controller (Lambregts, 1983; Lambregts et al., 2008).

A reservoir analogy (Figure 1), adapted from Amelink et al. (2005), illustrates the energy-based role of the throttle and the elevator for altitude and airspeed control. As shown in the diagram, the airplane gains energy through thrust $(T)$ and loses energy through $\operatorname{drag}(D)$ at rates indicated by $\dot{E}_{\mathrm{T}}$ and $\dot{E}_{\mathrm{D}}$, respectively. The net total energy flow $\dot{E}_{\mathrm{T}-\mathrm{D}}$, resulting from the difference between thrust and drag, determines whether the airplane's total energy $(E)$ - the sum of the energy contained in the altitude and airspeed "reservoirs"-increases, decreases, or remains constant. The throttle regulates the net total energy flow $\left(\dot{E}_{\mathrm{T}-\mathrm{D}}\right)$ while the elevator controls the distribution of this energy flow between altitude and airspeed. In other words, the throttle and elevator control the airplane's energy balance (Equation 6) - with the throttle controlling the left-hand "energy transfer" side $\left(\dot{E}_{\text {T-D }}\right)$ and the elevator controlling the right-hand "energy distribution" side $\left(\dot{E}_{\text {pot }}+\dot{E}_{\text {kin }}\right)$ of the equation. Thus, when the throttle increases thrust above drag $(T-D>0)$, there is a net positive energy flow raising the airplane's total energy, and when the throttle reduces thrust below drag $(T-D<0)$, there is a net negative energy flow decreasing the total energy. This positive or negative energy flow is distributed by the elevator into or out of the altitude and airspeed reservoirs at rates indicated by $\dot{E}_{\text {pot }}$ and $\dot{E}_{\text {kin }}$, respectively. Finally, when the throttle adjusts thrust equal to drag $(T-D=0)$, the net energy flow is zero, but the energy stored in the altitude and airspeed reservoirs can be exchanged using the elevator while total energy, in the short-term, remains constant. For a more extensive analysis of the reservoir analogy and its limitations see Amelink et al. (2005).

From a safety perspective, it is noteworthy that every inflight energy crisis starts as a deviation from the desired vertical flight path and/or airspeed. A key advantage of the energy approach to flight control is that it provides an effective strategy for correcting such deviations. Since the aircraft's total mechanical energy is distributed over potential and kinetic energy, one can distinguish two types of energy state deviations: 1) total energy errors and 2) energy distribution errors (Amelink et al., 2005). In the first case, the airplane has too little or too much total energy, but

Table 1

Strategies used to control airspeed and altitude.

\begin{tabular}{lll}
\hline Strategy & Throttle controls: & Elevator controls: \\
\hline SISO 1 & Airspeed & Altitude \\
SISO 2 & Altitude & Airspeed \\
TECS/MIMO & Total energy rate $(\dot{\mathrm{E}})$ & Distribution of energy between altitude $\left(\dot{\mathrm{E}}_{\text {pot }}\right)$ and airspeed $\left(\dot{\mathrm{E}}_{\text {kin }}\right)$ \\
\hline
\end{tabular}

Note: In "single-input, single-output" (SISO) control strategies, where the controls are not coordinated, a desired change in one variable (e.g., airspeed) is always coupled with a change in the other variable (e.g., altitude) resulting in unwanted and inefficient energy deviations. In contrast, in the energy-based "multi-input, multi-output" (TECS/MIMO) control technique, the throttle and elevator are coordinated to decouple altitude and airspeed. For a thorough analysis of these control strategies see Amelink et al. (2005) and Lambregts et al. (2008). 


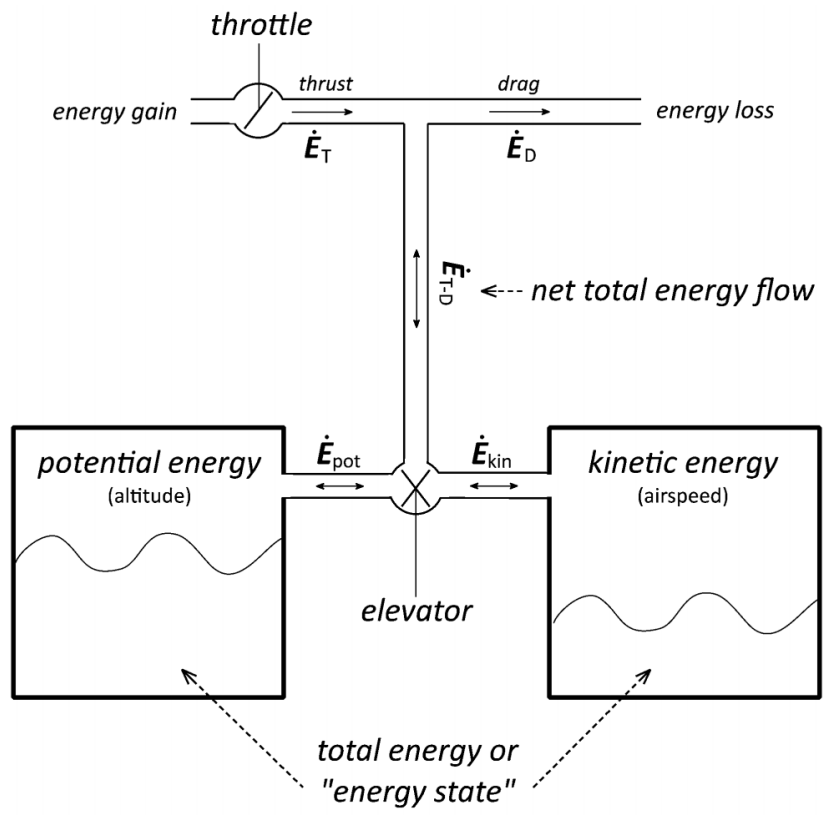

Figure 1. The reservoir analogy (adapted from Amelink et al., 2005) depicts the role of the throttle and elevator in controlling the aircraft's energy balance (see Equation 6). The throttle controls the "valve" regulating the net total energy flow while the elevator controls the "valve" regulating the distribution of energy between altitude and airspeed. The solid arrows represent energy flows, not relative direction of forces or airflows. Note that thrust $\left(\dot{E}_{\mathrm{T}}\right)$ and drag $\left(\dot{E}_{\mathrm{D}}\right)$ energy flows are unidirectional. Once energy from fuel is converted to thrust, it cannot flow back into the fuel tanks. Likewise, energy lost through drag to the environment is unrecoverable. In contrast, the net total energy flow $\dot{E}_{\mathrm{T}-\mathrm{D}}$ (resulting from the difference between thrust and drag) as well as the altitude $\left(\dot{E}_{\text {pot }}\right)$ and airspeed $\left(\dot{E}_{\text {kin }}\right)$ energy flows can switch directions as energy moves into or out the reservoirs. Finally, note that stored energy can also be exchanged between reservoirs without being lost to the environment.

its relative distribution over potential and kinetic energy may be correct. In total energy errors, altitude and speed deviations tend not to be inversely correlated, and thus both variables usually deviate in the same direction (e.g., low-and-slow or high-and-fast). In the second type of error, the aircraft may have the proper amount of total energy but its distribution over potential and kinetic energy is incorrect. In energy distribution errors, altitude and speed deviations tend to be inversely correlated and thus both variables typically deviate in opposite directions (e.g., high-and-slow or low-and-fast). According to TECS principles then, total energy errors should be corrected by increasing or decreasing energy using the throttle, while energy distribution errors should be corrected by exchanging energy between altitude and speed using the elevator (Amelink et al., 2005). When both total energy and its distribution are off, the pilot (or automatic flight control system) may need to mix the use of the flight controls accordingly to bring the airplane back into its proper energy state. In addition, once short-term control is achieved and energy deviations are corrected, the airplane will need to be trimmed for long-term control to maintain the desired vertical flight path and airspeed (Amelink et al., 2005).

\section{Military Science: Energy Maneuverability Theory}

Military researchers have long been interested in predicting optimal trajectories of fighter aircraft during air combat (Cliff, 1998; Kelley, Cliff, \& Weston, 1986; Rutowski, 1954; Wendl, Grose, Porter, \& Pruitt, 1974). Air combat models rely partly on energy maneuverability (EM) theory, an important concept linking the energy state of an airplane with its potential performance (Kelley et al., 1986; Shaw, 1985). Fighter pilots use energy tactics to outmaneuver and outperform their opponent during air combat (Kelley et al., 1986; Shaw, 1985).

One of the core concepts in EM theory is energy height or specific energy $\left(E_{\mathrm{s}}\right)$, which represents the idealized maximum altitude that the airplane would reach from its current altitude if it converted all its existing kinetic energy into potential energy (Cliff, 1998; Shaw, 1985). $E_{s}$ is measured in units of height (e.g., feet) and it corresponds to the total mechanical energy of the airplane - the sum of its potential and kinetic energies-divided by its weight:

$$
\mathrm{E} / \mathrm{W}=\left(\mathrm{mgh}+1 / 2 \mathrm{mV}^{2}\right) / \mathrm{W}
$$

Noting that $W=m g$, one can simplify the above equation to obtain:

$$
E_{\mathrm{s}}=h+V^{2} / 2 g
$$

Plotted on an altitude-velocity graph, $E_{\mathrm{s}}$ lines of constant energy height describe the energy state of the airplane for any given combination of altitude and airspeed (Figure 2). Thus, each $E_{\mathrm{S}}$ line on the graph represents an idealized instantaneous "zoom" along which kinetic (airspeed) and potential (altitude) energy may be exchanged back and forth while maintaining a constant energy state (Anderson, 2007;

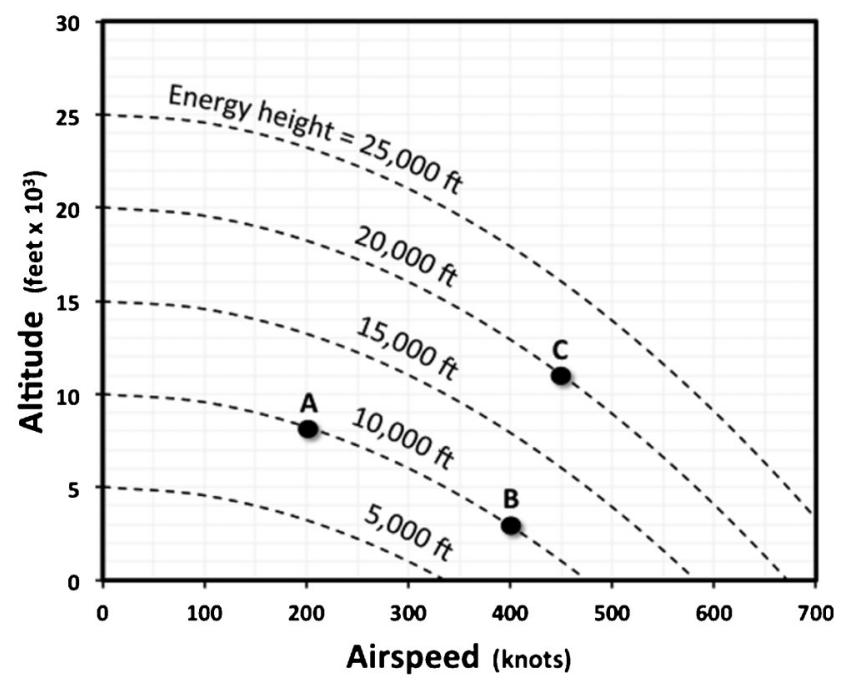

Figure 2. Altitude-velocity diagram, adapted from Anderson (2007), showing lines of constant specific energy $\left(E_{s}\right)$ or equal energy height. In this graph, (pressure) altitude is plotted in thousands of feet and (true) airspeed in knots. For supersonic aircraft, it is common to plot airspeed in Mach number instead of knots. 
Cliff, 1998; Shaw, 1985). In other words, by establishing the aircraft's current $E_{s}$ or energy height, the pilot can quickly determine the absolute maximum altitude or airspeed it could attain through energy exchange alone (Rutowski, 1954).

To grasp the significance of energy height, consider the three identical airplanes (i.e., of equal weight) depicted in Figure 2. Airplane $A$ is cruising at an altitude of 8,000 feet at approximately 200 knots while airplane $B$ is cruising at an altitude of 3,000 feet at about 400 knots. Although these two airplanes have a different combination of potential and kinetic energies, their total energy is the same and both are capable of zooming to a maximum altitude of 10,000 feet by trading speed for altitude. In other words, their energy height is 10,000 feet. Now, examine airplane $C$ cruising at 11,000 feet at roughly 450 knots. This airplane has a higher energy state than that of either airplane $A$ or $B\left(E_{s}=10,000\right.$ feet $)$ since the former can zoom to a maximum altitude of 20,000 feet without adding power. The only way for airplanes A and B to reach the energy height of airplane $C\left(E_{s}=20,000\right.$ feet $)$ is for the former to increase their total energy. In short, an airplane can move back and forth along a constant energy line (Figure 2) by exchanging energy (i.e., redistributing potential and kinetic energies while maintaining total energy constant). In contrast, an airplane cannot move across energy lines by simply exchanging energy-in order to go from one energy height to another, the airplane must increase or decrease its total energy. And this brings us to the next important concept in EM theory.

The rate of change of an aircraft's total energyallowing it to go from one energy height to another-is defined by the specific excess power or $P_{\mathrm{s}}$, which is excess power divided by the airplane's weight (Anderson, 2007; Cliff, 1998; Shaw 1985). $P_{\mathrm{s}}$ describes the aircraft's net total energy flow per unit weight as a function of the difference between thrust $(T)$ and drag $(D)$ :

$$
P_{\mathrm{s}}=(T-D) V / W
$$

Thus, a positive $P_{\mathrm{s}}$ represents the ability of an airplane to increase its energy state in order to climb (without slowing down) or accelerate (without losing altitude) to a higher energy height $\left(E_{\mathrm{s}}\right)$. Note that being a specific energy rate, $P_{\mathrm{s}}$ has the units of length/time (e.g., feet/min). The $P_{\mathrm{s}}$ capabilities of fighter aircraft are displayed on the same altitude-velocity graphs that are used to depict specific energy or energy height $\left(E_{\mathrm{s}}\right)$ lines. By plotting a series of excess power $\left(P_{s}\right)$ contours (derived from power-required/ power-available curves at different altitudes) on an altitudevelocity diagram, the pilot is able to determine the most optimal path to go from one energy level to another. In other words, this energy approach provides the optimal solution to get from any initial altitude and airspeed to another final altitude and airspeed within the airplane's performance envelope (Rutowski, 1954). For illustrations of $P_{\mathrm{s}}$ contours, see Schneider (2010).
The link between specific excess power $\left(P_{\mathrm{s}}\right)$ and energy height $\left(E_{\mathrm{s}}\right)$ can be made explicit by applying the energy balance principle described earlier-where the difference between energy gain and loss must equal the change in total energy of a system (Cengel, 2007). However, this time, energy rates are expressed on a per unit weight basis. Specific excess power $\left(P_{\mathrm{s}}\right)$ represents the airplane's rate of energy gain minus energy loss per unit weight, while the rate of change of energy height $\left(\dot{E}_{\mathrm{s}}\right)$ represents the rate of change of the airplane's total mechanical energy per unit weight. Thus, according to the energy balance principle, specific excess power must equal the rate of change of energy height (Rutowski, 1954):

$$
P_{\mathrm{s}}=\dot{E}_{\mathrm{s}}
$$

Since $P_{\mathrm{s}}=(T-D) V / W\left(\right.$ Equation 8) and $\dot{E}_{\mathrm{s}}=\dot{h}+\dot{V} V / g$ (derived from Equation 7), Equation 9 can be re-stated as follows:

$$
(T-D) V / W=\dot{h}+\dot{V} V / g
$$

Equation 10 simply says that specific [positive, negative, or zero] excess power $P_{\mathrm{s}}-$ a function of $T-D$ - can be distributed between altitude $(\dot{h})$ and airspeed $(\dot{V} V / g)$ changes. The close parallel between the energy balance equation and Newton's force equation described earlier (Equation 3) is no coincidence. The former can easily be derived from the latter (Anderson, 2007; Rutowski, 1954), pointing to the intimate relation between the laws of energy conservation and motion (Goodman \& Warner, 2001). Moreover, the same set of force and energy equations equally apply to flight control and aircraft performance.

Historically, the development of energy-based performance models (e.g., energy maneuverability) has preceded that of energy-based control models (e.g., TECS). The earliest model of energy maneuverability traces back to the early 1940s when Fritz Kaiser, a German flight test engineer, developed the concept of energy height (which he called "Gesamthöhe," meaning resulting height) working on the Messerschmitt 262-the first jet aircraft to become operational toward the end of World War II (Merritt, Cliff, \& Kelley, 1985). Kaiser was mainly interested in determining energy climb performance of the Me 262 (Merritt et al., 1985). Rutowski, working at the Douglas Aircraft Company, expanded and applied EM theory to include both climb and range performance (Rutwoski, 1954). More recently, Schneider (2010) elaborated EM theory incorporating the realm of negative $P_{s}$ ("negative excess power") to analyze the safety and efficiency of high-speed, steep angle dives. However, it was USAF Col. John Boyd who coined the term "energy maneuverability" in the 1960s (Coram, 2004). Boyd advanced the theory to new levels by comparing how the $P_{s}$ capabilities of different fighter aircraft vary with altitude, airspeed, and other factors such as G-loading, and determining how an energy advantage could be attained 
in air combat by maneuvering and rapidly changing from one energy state to another (Coram, 2004; Schneider, 2010).

\section{Biology: Structure-Function Integration and Energy Efficiency}

Biologists have had a long-standing interest in studying the integration of structure and function in living organisms (Russell, 1916). Structure-function relations have been extremely valuable to physiologists seeking to unravel the underlying principles of animal locomotion (Dickinson et al., 2000), where structure is determined by the anatomical features that control movement (Alexander, 2003; Dickinson et al., 2000) and function is measured through the physiological performance of running, swimming, or flying animals (Schmidt-Nielsen, 1972). One of the main themes that have emerged from these studies is that motion control and performance are tightly integrated through common mechanisms governing the use of locomotive forces and energy transfer, exchange, and storage (Dickinson et al., 2000). As suggested in this paper, this view is akin to focusing on the energy-based integration of flight control and aircraft performance, encapsulated in the airplane's energy balance equation.

Since the energy not used for locomotion is available for other important biological activities (e.g., growth and reproduction), it follows that animals should be economical in the use of energy for moving around (Alexander, 2003). Examples of energy-efficient strategies in flight include foraging behavior of hummingbirds (Chai, Chang, \& Dudley, 1998) and long-distance migration of geese (Cutts \& Speakman, 1994). Given the significance of energy savings in animal locomotion, biologists have sought general models for predicting and testing energy efficiency. One such model was developed by C. J. Pennycuick, a biologist at the University of Bristol, UK (Pennycuick, 2003). The fact that some migrating birds can fly astonishing airline-like distances of over 6,000 miles non-stop without refueling (Piersma \& Gill, 1998) prompted Pennycuick — himself a pilot - to focus on range performance.

The starting point in Pennycuick's model is the concept of energy height-described in the previous sectionrepresenting the maximum height that an airplane (or in this case, a bird) would reach from its present height by converting all of its stored kinetic energy into potential energy. However, Pennycuick generalized the concept of energy height and redefined it as a virtual height that a bird would reach if it converted any stored energy - such as fuel energy - into potential energy by doing work against gravity (Pennycuick, 2003). An immediate benefit of Pennycuick's approach is that stored fuel energy can be treated the same way as stored potential or kinetic energy when analyzing energy utilization in flight.
Next, Pennycuick drew a simple connection between energy height and distance flown, allowing him to link two distinct and fundamental processes that make up energy efficiency in flight: 1) converting chemical (fuel) energy into mechanical energy and 2) converting mechanical energy into motion. The first process, defining how efficiently mechanical energy is generated for flight, is the realm of engine performance; while the second process, defining how efficiently mechanical energy is spent in flight, is dictated by airframe aerodynamic performance (Anderson, 2007; Pennycuick, 2003).

To establish the connection between height and distance (and later between engine and aerodynamic performance), Pennycuick used gliding flight as a starting analogy. As a glider descends, the distance flown $(Y)$ is proportional to the starting height $(h)$ :

$$
Y=h N
$$

Equation 11 simply states that the horizontal distance covered $(Y)$ is equal to the product of the starting height (h) - representing the initial store of potential energy; times the glide ratio $(N)$ - a dimensionless number defining the gradient along which the bird or glider descends. The gradient $N$, which converts height into distance, is equal to the lift:drag ratio $L / D$-itself a function of airspeed. As a result, a glider covers the farthest distance $(Y)$ from a given starting height $(h)$ flying at one particular speed-the "best-glide" speed-where drag is minimized and $L / D$ is maximized (Pennycuick, 2003). At any other faster or slower speed, the angle of descent is steeper shortening the distance covered as the glider descends. Thus, the performance number $N$ or $L / D$ is at the heart of aerodynamic performance (Anderson, 2007; Pennycuick, 2003).

By analogy, in powered flight-where fuel energy, rather than potential energy, is used to overcome drag - the initial store of fuel can be transformed into a fuel energy height $\left(h_{\text {fuel }}\right)$, an imaginary height to which a given amount of fuel energy could "lift" a bird (or airplane) if it were converted into work (Pennycuick, 2003). In other words, $h_{\text {fuel }}$ is the maximum height that could theoretically be reached from converting all the fuel onboard into potential energy. Fuel energy height $\left(h_{\text {fuel }}\right)$ takes into account several factors such as the relative amount of fuel at departure, the efficiency by which fuel energy is progressively converted into work against gravity, and the gradual weight loss as fuel is burned (Pennycuick, 2003). Expressed in units of length, $h_{\text {fuel }}$ is a measure of engine performance in its simplest formdefining how efficiently mechanical energy is generated for flight. Completing the analogy, range $(R)$ in horizontal flight is proportional to the initial fuel energy height $\left(h_{\text {fuel }}\right)$ :

$$
R=h_{\text {fuel }} N
$$

As fuel is progressively consumed, the bird (or airplane) comes "down" from its initial fuel energy height along a 
virtual energy gradient $N$ (Pennycuick, 2003). As in gliding flight, $N$ measures aerodynamic performance-governing how efficiently mechanical energy is spent during flight. For birds and propeller aircraft in powered flight, $N$ is equal to the lift:drag ratio, exactly as it is in gliding flight (Pennycuick, 2003); while for jet aircraft $N$ is equal to the ratio of the square root of the coefficient of lift to the coefficient of drag (Anderson, 2007). Maximum range, for a given fuel energy height, is achieved at the airspeed where $L / D$ (or $C_{\mathrm{L}}^{1 / 2} / C_{\mathrm{D}}$ in jets) is maximized. In sum, measuring range $(R)$, a quintessential representation of energy efficiency in long-distance flight, boils down to calculating and multiplying two quantities (Equation 12): 1) an engine performance number or fuel energy height $\left(h_{\text {fuel }}\right)$ in units of length (e.g., feet or miles) - defining how effectively mechanical energy is extracted from fuel-and 2) a dimensionless aerodynamic performance number or energy gradient $(N)$-dictating how efficiently mechanical energy is converted into mileage.

In his unique approach then, Pennycuick (2003) took the energy height concept - formulated years earlier to enhance air combat tactics for fighter jet pilots (Merritt et al., 1985; Shaw, 1985) - and expanded it to solve the mystery of long-range migration in birds. Interestingly, Rutowski (1954) used yet a different energy approach, focusing on the airplane's energy balance to arrive at an equivalent range equation, again underlining the usefulness of energybased methods for solving performance problems across disciplines.

Having examined energy management concepts-such as energy balance, specific excess power, and energy height - and established their usefulness for exploring and defining the role of the flight controls and the aircraft's performance limits, the next section focuses on the merits of a top-down energy approach as an instructional tool.

\section{Pedagogical Basis for Energy Management Training}

The instructional value of an energy-centered approach for pilot training was examined some years ago (Merkt, 1990; 1991; 1992). Figure 3 illustrates two opposite approaches to learning principles of flight. The traditional approach is comparable to that employed by early aeronautical engineers designing airplanes (e.g., Warner, 1936), while the alternate approach is analogous to that used by physiologists studying animal motion (e.g., Schmidt-Nielsen, 1972).

\section{Bottom-up "Designer" Approach}

Traditionally, engineers begin by examining the underlying causes (e.g., fluid properties), as opposed to top consequences (e.g., flight performance), of aerodynamic phenomena in order to understand principles they can apply to design airplanes (Warner, 1936). For design engineers, the "finished product" at the end of the process is not just the physical airplane but its performance, best represented by power-curves or drag polars (Anderson, 2007; von Mises, 1945). In a nutshell, design engineers use a bottomup approach (Figure 3). This approach is most obvious in traditional aerodynamics textbooks (e.g., von Mises, 1945) as well as those dealing with theory of flight for pilots (e.g.,

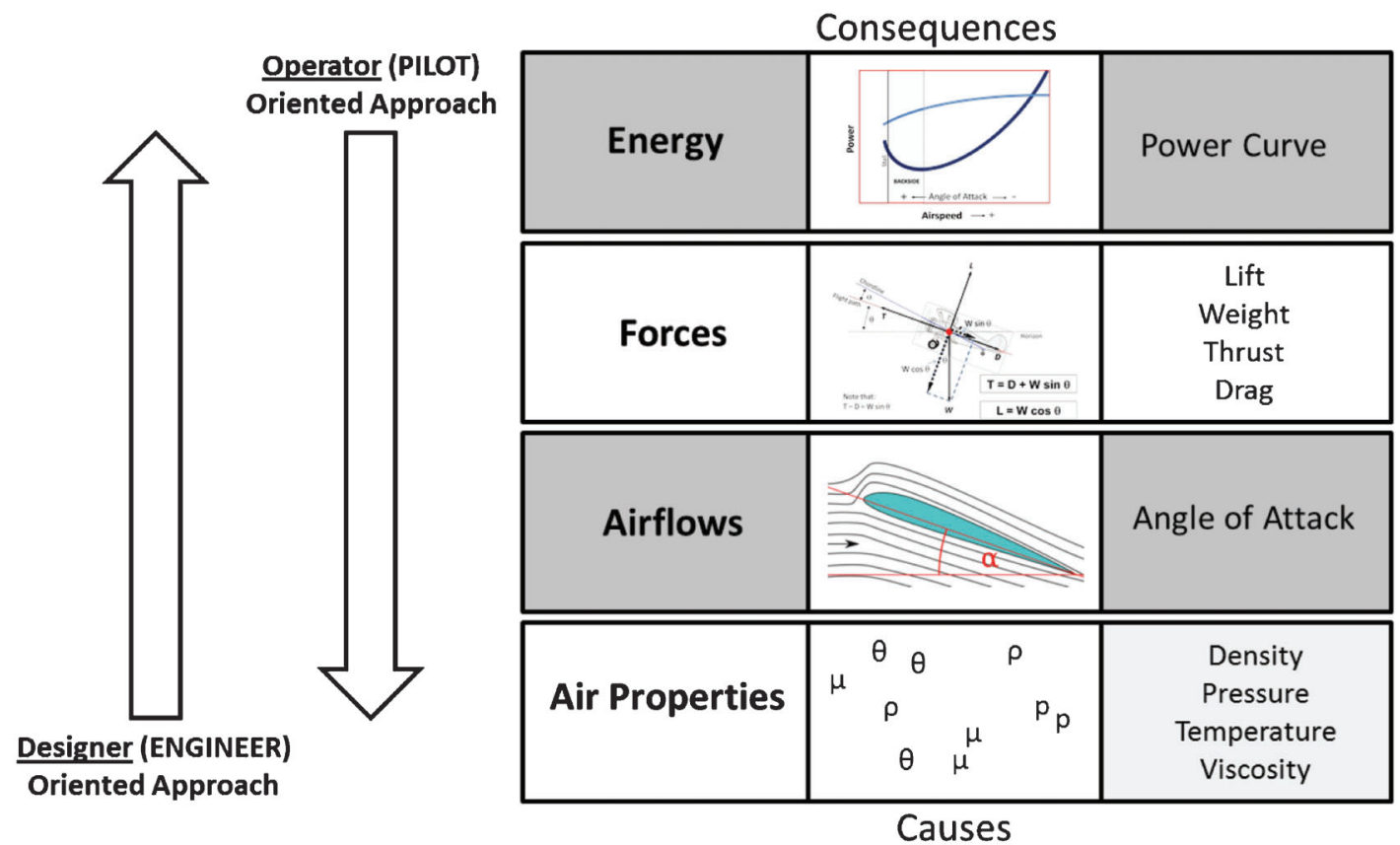

Figure 3. Two opposite approaches to the study and practice of flight (adapted from Merkt, 1990). The designer (engineer) oriented approach starts by studying the causes of aerodynamic phenomena (e.g., fluid properties) and proceeds up to higher-level consequences (e.g., aircraft performance). The operator (pilot) oriented approach starts with the highest consequences of aerodynamic processes and proceeds downward to unravel underlying principles. 
Dole, 1989; Hurt, 1965). This traditional method of teaching basic principles can be viewed as the designer approach (Merkt, 1990).

The problem with the bottom-up training approach is that it often introduces basic concepts as isolated "parts" (Hadjilogiou, 2001; Merkt, 1990). Without the proper "big picture" context and a solid background in physics and mathematics, it may be difficult for students to grasp the theoretical-let alone practical-significance of abstract concepts such as "lift" or "angle of attack," which they cannot "see" or "feel" during training flights (Merkt, 1990). Later in the training, when the big picture (e.g., aircraft performance) is presented, several underlying elements of the theory are omitted, since their understanding is taken for granted. The result is often a pilot who possesses basic flying skills but lacks satisfactory understanding of aircraft performance and its underlying principles (Merkt, 1990).

Top-down “Operator” Approach

Merkt (1990) suggested an alternate approach to teaching principles of flight. Rather than starting with the underlying causes of flight (e.g., properties of air), one can unravel basic principles by starting with aerodynamic consequences (e.g., flight performance). This approach is analogous to that used by physiologists who begin their study of animal locomotion by obtaining metabolic power (energy rate) measurements of animals running on treadmills or flying in wind tunnels at different steady speeds (Schmidt-Nielsen, 1972). The physiologist's top-down approach is thus diametrically opposite to that of design engineers. After all, physiologists begin their studies with a "finished product," namely a live, performing animal. They need to start at the "top" and work their way "down" to unravel the underlying principles of animal locomotion (Merkt, 1990).

In an analogous manner, one can focus on the airplane's energy balance and use power-required and power-available curves to begin the study of mechanical flight (Merkt, 1990). Just like physiologists, pilots have to deal with a "finished product" - a functioning airplane. The top-down approach (energy $\rightarrow$ forces $\rightarrow$ airflows) to studying flight could be viewed as being operator (pilot) oriented (Figure 3). The bottom-up approach has proven ideal to teach principles of flight to engineering students, but the opposite approach may be more suitable for teaching the same principles to student pilots (Merkt, 1990).

Why should one start at the top, looking first at energy concepts such as the law of energy conservation, to learn basic principles of flight? Physicist Richard Feynman put it best:

The conservation of a physical quantity is of considerable interest because in solving problems it permits us to forget a great number of details. The conservation of energy can be derived from the laws of motion, but its value lies in the fact that by the use of it certain broad aspects of a problem may be discussed, without going into the great detail that is often required by a direct use of the laws of motion. (Feynman, 1942, p. 12)

In other words, by focusing first on energy concepts, a student pilot can learn a great deal about flight without having to dig down too deeply into complex underlying mechanisms. Should there be a need to dig down, the topdown approach guides students through distinct explanation "levels" (Figure 3) - each containing the underlying elements that explain the next level up. By starting at the top, students only need to focus on the level immediately below to begin their search for explanations. These underlying principles, however, only emerge in the context of the "big picture" model represented by the top level. Students view relevant components within a meaningful context and begin to appreciate how these basic elements interact in different phases of flight, such as slow flight (Merkt, 1990). Thus, a top-down approach can serve not only as a practical guiding tool in course design, organization, and delivery, but also as a powerful learning tool to help pilots develop a correct mental model of how the airplane works right from the start.

The case for switching from a bottom-up to a top-down educational approach has been made in other professional disciplines as well. Examples of adoption of a top-down approach include college courses in computer design (Franklin \& Noakes, 1995), electronics (Hadjilogiou, 2001; Molin, 2002), and mechanical engineering (Covill, Katz, \& Morris, 2007). Preliminary assessment indicates that top-down learning, where students are first exposed to the "whole" rather than the isolated "parts," leads not only to better understanding of the subject matter (Covill et al., 2007; Hadjilogiou, 2001) but also to greater motivation to learn (Molin, 2002).

\section{Conclusion}

The prevalence of in-flight energy crises leading to accidents (Airbus, 2005; Boeing, 2012; Jacobson, 2010) and the impact of wasted energy on increased operating costs (Airbus, 2004; Berglund, 2008; Boeing, 2004) suggest a need for better energy management training for pilots. Energy is a fundamental, yet somewhat neglected, concept in the study and practice of flight. Altitude and airspeed - the essential elements of flight — are inescapably linked through the laws of energy conservation and motion, two of the most profound and farthest-reaching concepts in all physics (Lewin \& Goldstein, 2011). As suggested here, energy management provides an ideal venue for examining safety and efficiency trade-offs. In addition, principles such as energy balance are powerful tools for exploring and 
Table 2

Key attributes of future flight energy management training program.

\begin{tabular}{|c|c|c|}
\hline Integrated & Energy-centered & Top-down \\
\hline $\begin{array}{l}\text { It links the safety and efficiency sides of } \\
\text { energy management by incorporating and } \\
\text { prioritizing strategies to 1) mitigate hazards } \\
\text { caused by unsafe energy states and to 2) } \\
\text { conserve fuel in all phases of flight. }\end{array}$ & $\begin{array}{l}\text { It applies energy management principles—such } \\
\text { as energy balance, specific excess power, } \\
\text { and energy height--to explore and define 1) } \\
\text { the role of the flight controls and 2) the } \\
\text { aircraft's performance envelope. }\end{array}$ & $\begin{array}{l}\text { It uses a top-down learning approach to 1) unravel } \\
\text { the fundamentals of flight; 2) assist in course } \\
\text { design, organization, and delivery; and 3) help } \\
\text { develop a correct mental model of how the } \\
\text { airplane works. }\end{array}$ \\
\hline
\end{tabular}

defining the role of the flight controls and the airplane's performance envelope. Moreover, learning to view an airplane in motion as an energy system can lead to an improved mental model of how the airplane works and, in doing so, to enhanced energy management and decisionmaking skills for safe and efficient operations. What then are the key attributes of an effective flight energy management training program? Combining ideas from physics, engineering, military science, and biology, this study proposes an integrated, energy-centered, top-down training approach (Table 2). A model curriculum, comprising ground and flight training syllabi, will be discussed in a future publication. Such a model could serve as a starting point for the design of energy management training courses for various users such as collegiate programs, flight training providers, airlines, corporate flight departments, and UAS operators.

I would like to thank Tony Lambregts for providing me with a historical account of the Total Energy Control System. I am indebted to Matthijs Amelink for allowing me to adapt his Energy Reservoir Analogy. I am grateful to Colin Pennycuick for sharing further insight into his Fuel Energy Height model, equally applicable to mechanical and bird flight, and to Eugene Cliff for pointing out the origins of the energy height concept. Additionally, I am thankful for the many people who read earlier versions of the manuscript and provided valuable comments, including Rodger Kram, Brian Lane, Wayne Phillips, BJ Smith, Ernie Strange, Brian Vaivadas, and my colleagues at the Davis Aviation Center. Finally, I want to thank my wife, Lanette, for patiently listening to the "energy management" story over and over and for her invaluable support, encouragement, and suggestions during manuscript preparation.

\section{References}

AABI. (2012a). Form 201: Accreditation Criteria Manual. July 2012. Retrieved from http://www.aabi.aero/forms.html

AABI. (2012b). Accredited Programs. Retrieved from http://www.aabi. aero/programs.html

Airbus. (2004). Getting to grips with fuel economy. Airbus Customer Services, Flight Operations Support \& Line Assistance, 4, 1-80. Retrieved from http://www.aiaa.org/pdf/student/01_Airbus_Fuel_ Economy_Material.pdf

Airbus. (2005). Aircraft energy management during approach. Airbus Customer Services, Flight Operations Briefing Notes. Retrieved from http://www.airbus.com/fileadmin/media_gallery/files/safety_library_ items/AirbusSafetyLib_-FLT_OPS-APPR-SEQ03.pdf
Alexander, R. M. (2003). Principles of animal locomotion. Princeton, NJ: Princeton University Press.

Amelink, M. H. J., Mulder, M., van Paassen, M. M., \& Flach, J. M. (2005). Theoretical foundations for a total energy-based perspective flight path display. The International Journal of Aviation Psychology, 15(3), 205-231.

Anderson, J. D. (2007). Introduction to flight (3 ${ }^{\text {rd }}$ ed.). New York: McGraw-Hill.

Barnard, R. H., \& Philpott, D. R. (1989). Aircraft flight: A description of the physical principles of aircraft flight. Essex, England: Longman Scientific \& Technical.

Berglund, T. (2008). Evaluation of fuel saving for an airline. Bachelor Thesis in Aeronautical Engineering, Mälarden University, Sweden. Retrieved from http://www.diva-portal.org/smash/get/diva2:121168/ FULLTEXT01.pdf

Boeing. (2004). Fuel conservation. Boeing Commercial Airplanes, Flight Operations Engineering. Retrieved from http://www.jetbrief.com/ library/fuel_conservation.pdf

Boeing. (2011). Boeing challenges industry to meet unprecedented demand for aviation personnel. Boeing, Media, June 22, 2011. Retrieved from http://boeing.mediaroom.com/index.php?s=43\& item $=1809$

Boeing. (2012). Statistical summary of commercial jet airplane accidents: Worldwide operations 1959-2011. Boeing Commercial Airplanes, Aviation Safety. Retrieved from http://www.boeing.com/news/ techissues/pdf/statsum.pdf

BTRE. (2006). Cost of aviation accidents and incidents. BTRE Report 113. Bureau of Transport and Regional Economics, Department of Transport and Regional Services. Australian Government. Retrieved from http://www.bitre.gov.au/publications/36/Files/BTRE_R113.pdf

Cengel, Y. A. (2007). Introduction to thermodynamics and heat transfer $\left(2^{\text {nd }}\right.$ ed.). New York: McGraw-Hill.

Chai, P., Chang, A. C., \& Dudley, R. (1998). Flight thermogenesis and energy conservation in hovering hummingbirds. The Journal of Experimental Biology, 201, 963-968.

Clark, D. (2005). Approach and landing accident reduction (ALAR) and energy management. The Mobility Forum, May/June, 2005, 4-6.

Cliff, E. M. (1998). Energy-state models. Retrieved from http://www.dept. aoe.vt.edu/ cliff/aoe3104_01/notes/Kaiser.pdf

Coram, R. (2004). Boyd: The fighter pilot who changed the art of war. New York: Back Bay Books.

Covill, D., Katz, T., \& Morris, R. (2007). A top down approach to teaching engineering mechanics. In International Symposium for Engineering Education, 2007, Dublin City University, Ireland.

Cox, J. M. (2010). Prioritizing mitigations in flight path management accidents. Safety Operations Systems: Technical Rep., June 2010. Retrieved from www.safeopsys.com/docs/Flight_Path_Accidents.pdf

Cutts, C. J., \& Speakman, J. R. (1994). Energy savings in formation flight of pink-footed geese. Journal of Experimental Biology, 189, 251-261.

Denker, J. S. (2008). See how it flies: A new spin on the perceptions, procedures and principles of flight. Retrieved from http://www.av8n. com/how/

Dickinson, M. H., Farley, C. T., Full, R. J., Koehl, M. A. R., Kram, R., \& Lehman, S. (2000). How animals move: An integrative view. Science, 288, 100-106. 
Dole, C. E. (1989). Flight theory for pilots. Casper, WY: I.A.P., Inc.

Duggar, J. W., Smith, B. J., \& Harrison, J. (2009). International supply and demand for U. S. trained commercial airline pilots. Journal of Aviation Management and Education, 1. Retrieved from http://www.aabri.com/ manuscripts/09349.pdf

EAA. (2011). Ten years of accidents and causal factors. Advocacy Update: Government Issues. EAA Sports Aviation, June 2011. Retrieved from http://www.sportaviationonline.org/sportaviation/ 201106?pg=11\#pg11

FAA. (2003). Glider flying handbook. FAA-H-8083-13. U.S. Department of Transportation, Federal Aviation Administration, Flight Standards Service. Retrieved from http://www.faa.gov/library/manuals/aircraft/ glider_handbook/

FAA. (2008). Airplane upset recovery training aid, Revision 2, November, 2008. Retrieved from http://www.faa.gov/other_visit/aviation industry/airline_operators/training/media/AP_UpsetRecovery_Book. pdf

FAA. (2011a). Title 14-Aeronautics and Space, Chapter 1-Federal Aviation Administration, U.S. Department of Transportation: Parts 61 (Certification for Pilots, Flight Instructors, and Ground Instructors), 121 (Certification for Air Carriers), 135 (Certification for Commuter and On-Demand Carriers), 141 (Certification for Pilot Schools), and 142 (Certification for Training Centers). Retrieved from http://ecfr. gpoaccess.gov/cgi/t/text/textidx?sid=782f473e28a14b79979f56be3blda $32 \mathrm{~d} \& \mathrm{c}=$ ecfr\&tpl $=/$ ecfrbrowse/Title14/14cfrv3_02.tpl

FAA. (2011b). Federal Aviation Administration, U.S. Department of Transportation: Airman Practical Test Standards (PTS) for Flight Instructors, Instrument Rating, Airline Transport Pilot, Commercial Pilot, and Private Pilot. Retrieved from http://www.faa.gov/training testing/testing/airmen/test_standards/

Feynman, R. P. (1942). The principle of least action in quantum mechanics (Doctoral dissertation, Princeton University). In L. M. Brown (Ed.), (2005). Feynman's thesis: A new approach to quantum theory (pp. 169). Hackensack, NJ: World Scientific Pub.

Franklin, M., \& Noakes, P. D. (1995). A computer based learning approach to teaching top down digital design. In IEE Colloquium on Computer Based Learning in Electronic Education, 11, 1-3.

Goodman, L. E., \& Warner, W.H. (2001). Dynamics. Mineola, NY: Dover Publications.

Hadjilogiou, J. (2001). An innovative top-down approach to teaching engineering courses. In 31st ASEE/IEEE Frontiers in Education Conference, October 10-13, 2001 Reno, NV. Retrieved from http://fieconference.org/fie2001/papers/1395.pdf

Hubin, W. N. (1992). The science of flight: Pilot-oriented aerodynamics. Ames, IA: Iowa State University Press.

Hurt, H. H. (1965). Aerodynamics for naval aviators. University of Southern California, United States Navy, 1960, NAVWEPS 00-80T80, Revised January 1965. The Office of the Chief of Naval Operations, Aviation Division.

Jacobson, S. R. (2010). Aircraft loss of control: Causal factors and mitigation challenges. American Institute of Aeronautics and Astronautics, 2010-8007. AIAA Guidance, Navigation, and Control Conference, Toronto, Ontario, Aug. 2-5, 2010.

Kelley, H. J., Cliff, E. M., \& Weston, A. R. (1986). Energy state revisited. Optimal Control Applications \& Methods, 7, 195-200.
Lambregts, A. A. (1983). Integrated system design for flight and propulsion control using total energy principles. In AIAA Aircraft Design, Systems and Technology Meeting. AIAA-83 2561.

Lambregts, T., Rademaker, R., \& Theunissen, E. (2008). A new ecological primary flight display concept. In 27th Digital Avionics Systems Conference, Oct. 26-30, 2008, St. Paul, MN, 4.A.1-1-4.A.1-20.

Langewiesche, W. (1944). Stick and rudder: An explanation of the art of flying. New York: McGraw-Hill.

Lewin, W., \& Goldstein, W. (2011). For the love of physics. New York: Free Press.

Merkt, J. R. (1990). The power curve: Teaching the essentials of flight. Collegiate Aviation Review, University Aviation Association Fall Conference Proceedings, Fall 1990.

Merkt, J. R. (1991). Aerodynamics from the top-down. Flight Training, $3(12), 28-36$.

Merkt, J. R. (1992). The power curve's other side: Secrets of flight control, fuel economy, and energy management. Flight Training, 4(1), 26-33.

Merritt, S. R., Cliff, E. M., \& Kelley, H. J. (1985). Energy-modeled climb and climb-dash: The Kaiser technique. Automatica, 21(3), 319-321.

Molin, B. (2002). A top down approach to learn basic electronics. Trita2IT Rapport 2002:1. Royal Institute of Technology, Applied Information Technology. Retrieved from http://gupea.ub.gu.se/ bitstream/2077/18123/1/gupea_2077_18123_1.pdf

Pennycuick, C. J. (2003). The concept of energy height in animal locomotion: Separating mechanics from physiology. Journal of Theoretical Biology 224, 189-203.

Piersma, T., \& Gill, R. E. (1998). Guts don't fly: Small digestive organs in obese bar tailed godwits. Auk, 115, 196-203.

Russell, E. S. (1916). Form and function: A contribution to the history of animal morphology. London, UK: John Murray.

Rutowski, E. S. (1954). Energy approach to the general aircraft performance problem. Journal of the Aeronautical Sciences, 21(3), 187-195.

Schmidt-Nielsen, K. (1972). Locomotion: Energy cost of swimming, flying, and running. Science, 177, 222-228.

Schneider, M. (2010). Dive angle sensitivity analysis for flight test safety and efficiency (Master's thesis). Department of the Air Force, Air University. Retrieved from http://www.dtic.mil/cgi-bin/GetTRDoc? $\mathrm{AD}=\mathrm{ADA} 517530$

Shaw, R. L. (1985). Fighter combat: Tactics and maneuvering. Annapolis, MD: Naval Institute Press.

Stolzer, A. J. (2002). Fuel consumption modeling of a transport category aircraft using flight operations quality assurance data: A literature review. Journal of Air Transportation, 7(1), 93-102.

Szurovy, G., \& Goulian, M. (1994). Basic aerobatics. Blue Ridge Summit, PA: Tab Books.

Vause, K. (2004). Fueling historical losses: How rising fuel costs have exposed strategic flaws in the airline industry. Virtual Strategist, 6. Retrieved from http://www.virtualstrategist.net/pdf/6-2-1.pdf

von Mises, R. (1945). Theory of flight. New York: McGraw-Hill.

Warner, E. P. (1936). Airplane design: Performance. New York: McGrawHill.

Wendl, M. J., Grose, G. G., Porter, J. L., \& Pruitt, V. R. (1974). Flight/ propulsion control integration aspects of energy management. In Society of Automotive Engineers, Air Transportation Meeting, April 30-May 2, 1974. 